See discussions, stats, and author profiles for this publication at: https://www.researchgate.net/publication/320292984

\title{
Sensitivity of Computed Tomography for the Assessment of Spontaneous Dermoid Cyst Localized Rupture with Granulomatous Reaction
}

Article in Seminars in Ophthalmology · October 2017

DOI: 10.1080/08820538.2017.1375126

\section{CITATIONS}

10 authors, including:

Alicia Galindo-Ferreiro

Hospital Universitario "Rio Hortega"

87 PUBLICATIONS 91 CITATIONS

SEE PROFILE

Hind M Alkatan

King Saud University

173 PUBLICATIONS 534 CITATIONS

SEE PROFILE

Some of the authors of this publication are also working on these related projects:

Laser em cirurgia de implantes View project

Project Molecular Basis of Ablepharon Macrostomia Syndrome View project
Sahar M ELKhamary

Mansoura University

108 PUBLICATIONS 841 CITATIONS

SEE PROFILE

Rajiv Khandekar

King Khaled Eye Specialist Hospital

188 PUBLICATIONS 1,813 CITATIONS

SEE PROFILE 


\title{
Sensitivity of Computed Tomography for the Assessment of Spontaneous Dermoid Cyst Localized Rupture with Granulomatous Reaction
}

\author{
Alicia Galindo-Ferreiro, Sahar M Elkhamary, Saif Aldossari, Patricia M. \\ Akaishi, Hind Alkatan, Rajiv Khandekar, Denny Marcos Garcia, Yerena \\ Muiños-Diaz, Silvana A Schellini \& A. Augusto V. Cruz
}

To cite this article: Alicia Galindo-Ferreiro, Sahar M Elkhamary, Saif Aldossari, Patricia M. Akaishi, Hind Alkatan, Rajiv Khandekar, Denny Marcos Garcia, Yerena Muiños-Diaz, Silvana A Schellini \& A. Augusto V. Cruz (2017): Sensitivity of Computed Tomography for the Assessment of Spontaneous Dermoid Cyst Localized Rupture with Granulomatous Reaction, Seminars in Ophthalmology, DOI: $10.1080 / 08820538.2017 .1375126$

To link to this article: http://dx.doi.org/10.1080/08820538.2017.1375126

Published online: 09 Oct 2017.

Submit your article to this journal

$Q^{2}$

View related articles $\asymp$

View Crossmark data $\widetilde{\nearrow}$ 


\title{
Sensitivity of Computed Tomography for the Assessment of Spontaneous Dermoid Cyst Localized Rupture with Granulomatous Reaction
}

\author{
Alicia Galindo-Ferreiro ${ }^{1,2}$, Sahar M Elkhamary ${ }^{1,3}$, Saif Aldossari ${ }^{1}$, Patricia M. Akaishi ${ }^{4}$, Hind \\ Alkatan $^{6}$, Rajiv Khandekar ${ }^{1}$, Denny Marcos Garcia ${ }^{4,5}$, Yerena Muiños-Diaz ${ }^{7}$, Silvana A \\ Schellini ${ }^{1,8}$, and A. Augusto V. Cruz ${ }^{4}$ \\ ${ }^{1}$ Department of Oculoplastic, King Khaled Eye Specialist Hospital, Riyadh, Saudi Arabia, ${ }^{2}$ Department of \\ Ophthalmology, Complejo Asistencial de Palencia, Palencia, Spain, ${ }^{3}$ Department of Diagnostic Radiology, \\ Mansoura Faculty of Medicine, Mansoura, Egypt, ${ }^{4}$ Department of Ophthalmology, Otorhinolaryngology and \\ Head and Neck Surgery, School of Medicine of Ribeirao Preto, University of Sao Paulo, Sao Paulo, Brazil, \\ ${ }^{5}$ Craniofacial Research Support Centre, University of Sao Paulo, Sao Paulo, Brazil, ${ }^{6}$ King Saud University \\ College of Medicine, Riyadh, Saudi Arabia, ${ }^{7}$ Hospital Nuestra Señora de Fátima, Vigo, Spain, and ${ }^{8}$ Faculdade \\ de Medicina de Botucatu, State University of Sao Paulo-UNESP, Sao Paulo, Brazil
}

\begin{abstract}
Purpose: To assess the sensitivity of computed tomography for the diagnosis of spontaneous localized orbital dermoid cyst rupture with granulomatous reaction. Methods: The charts of 42 patients with dermoid cysts were reviewed retrospectively. The data collected included demographics, clinical features, CT imaging, and postoperative histopathological analysis of the lesions. The association between radiological signs of inflammation and histopathological evidence of an inflammatory reaction was tested by univariate logistic regression. Results: Localized spontaneous rupture with granulomatous reaction occurred in $61.9 \%$ of patients. The median age of patients with spontaneous rupture was significantly higher than the age of patients who had no histopathological evidence of rupture. Bone scalloping was significantly associated with preoperative rupture. Fat contents had a protective effect. Large sizes increased the odds of rupture. Conclusion: Bone remodeling and histopathological evidence of spontaneous preoperative rupture were significantly associated. Since age, cyst size, and contents are factors contributing to rupture, surgical removal is suggested for dermoids with liquid contents.
\end{abstract}

Keywords: Dermoids, histology, imaging, orbit, surgery

\section{INTRODUCTION}

The dermoid cyst (DC) is a benign congenital lesion derived from the ectoderm and mesoderm. Orbital DCs are usually diagnosed in childhood near sites of developmental fusion of bones, such as the fronto-zygomatic and fronto-ethmoidal suture. ${ }^{1}$ Since DCs tend to expand, provoking bone destruction, they are typically managed with surgical excision. ${ }^{2}$

The contents of any DC can leak due to the rupture of its capsule during surgical dissection or spontaneously as the dermoid grows. Spontaneous rupture is often clinically asymptomatic if there is no associated leakage of contents and the epidermal wall is simply replaced by localized granulomatous reaction. On the other hand, this rupture may induce fibrosis around the cyst and adherence of the cyst wall to the adjacent soft tissues and bony walls of the orbit. ${ }^{1,3}$ It is thus important, from a surgical point of view, to detect any evidence of spontaneous rupture. In the present study, we assessed the sensitivity of computed tomography (CT) for the prediction of spontaneous rupture of orbital DCs. 


\section{METHODS}

We retrospectively reviewed the medical records, CT scans, and histopathological specimens of 42 consecutive patients who underwent excision of orbital DCs at the King Khaled Eye Specialist Hospital (KKESH), Riyadh, Kingdom of Saudi Arabia. Clinical data were collected regarding age, gender, laterality, presence of symptoms, and intraoperative complications. Only patients with available CT scans and histopathological analysis of the surgical specimens were included in the study.

The presene of chronic inflammatory cells in or near the pseudo capsule of the DC, with or without giant cells or frank granulomata detected by histopathological analysis of the specimens, was taken as confirmation of cyst rupture prior to surgical intervention. ${ }^{4}$ This chronic inflammation was graded as mild, moderate, or severe, depending on the intensity of the infiltration by the chronic inflammatory cells.

Multislice CT scans were performed with a Discovery 750 HD 64-slice unit (GE Healthcare, Little Chalfont, UK). All images were obtained in a high-resolution bone window level setting (tube voltage $120 \mathrm{Kv}$, gantry tilt: $0^{\circ}$, matrix $512 \times 512$ ) including $1 \mathrm{~mm}$ thickness and a $0.5 \mathrm{~mm}$ increment with the patient's head positioned parallel to the Frankfurt plane. Bone and soft tissue algorithm reconstructions were available for review.

$\mathrm{CT}$ data were collected about cyst location relative to the orbital septum (superficial or deep), size, appearance of the lesion contents (fat/fluid or mixed), presence of bone scalloping, and soft tissue abnormalities associated with the DCs. Ill-defined lesions with an irregular outline, dirty surrounding fat, and dense heterogeneous content with peripheral enhancement were considered to be radiological signs of preoperative spontaneous rupture.

\section{Statistical Analysis}

The nonparametric Mann-Whitney test was used to compare the median values of quantitative variables.
The association between CT findings and histopathological analysis of spontaneous rupture was determined by univariate logistic regression (Wald test).

\section{RESULTS}

Median patient age was five years (range: 1-42 years). Of the 42 cysts, $85.7 \%$ were superficial and $14.3 \%$ were deep. The age of patients with spontaneous rupture (median $=5.5$ years) was significantly higher than the age (median $=3.0$ years) of patients who did not show any histological evidence of rupture $(p=0.035)$. Patient demographics and features of the preoperative rupture group and non-rupture group are compared in Table 1.

All DCs were lined by keratinizing stratified squamous epithelium with skin appendages. The cavity of the cysts contained keratin material in a multilayered fashion. Some cysts also contained hair shafts. None of the spontaneously ruptured cysts had a collapsed cavity. Rather, the epidermal-like wall was simply interrupted and replaced by a granulomatous reaction consisting of numerous epithelioid cells and giant cells (Figure 1). Some of the giant cells surrounded sebaceous material and had a slightly foamy appearance. A mild to moderate chronic inflammatory cell reaction was observed within the fibrous and soft tissue surrounding the ruptured cyst wall. Small portions of the original epidermal wall were observed in some ruptured cysts but, in most cases, inflammatory fibrous tissue constituted most of the cyst wall. The chronic inflammatory cells were a variable mixture of mature lymphocytes and reactive plasma cells. Just one case of ruptured DC showed a severe inflammatory response consisting of granulomatous inflammation with no well-defined residual epidermal lining.

The CT scan features of both groups are presented in Table 2. The odds-ratio of size (1.08) indicated that, for each millimeter of increase in the dimension of the cyst, the chances of its rupture increased by $8 \%$. Size was also linearly correlated with age $(y=9.12+0.69 x ; r=0.71$,

TABLE 1. Demographic distribution of orbital dermoid cysts.

\begin{tabular}{|c|c|c|c|c|c|c|}
\hline & & \multicolumn{4}{|c|}{ Spontaneous Rupture } & \multirow[b]{3}{*}{$P$ Value } \\
\hline & & \multicolumn{2}{|c|}{ Yes $(n=26)$} & \multicolumn{2}{|c|}{ No $(n=16)$} & \\
\hline & & Number & $\%$ & Number & $\%$ & \\
\hline \multirow[t]{2}{*}{ Gender } & Male & 12 & 46.1 & 8 & 50 & \multirow{2}{*}{$0.80^{* *}$} \\
\hline & Female & 14 & 53.9 & 8 & 50 & \\
\hline \multirow[t]{2}{*}{ Side of orbit } & Right & 16 & 61.5 & 7 & 43.8 & \multirow[t]{2}{*}{$0.26^{* *}$} \\
\hline & Left & 10 & 38.5 & 9 & 56.2 & \\
\hline \multirow[t]{3}{*}{ Symptoms } & Mass & 23 & 88.5 & 16 & 100 & \multirow[t]{3}{*}{-} \\
\hline & Inflammation & 1 & 3.8 & 0 & 0.0 & \\
\hline & None & 2 & 7.7 & 0 & 0.0 & \\
\hline Duration of follow-up (months) & Median (range) & \multicolumn{2}{|c|}{$0.5(0.01-5.3)$} & \multicolumn{2}{|c|}{$1.5(0.01-107)$} & 0.20 * \\
\hline
\end{tabular}

*Mann-Whitney Test; ${ }^{* *}$ Chi-square Test; $p<0.05$ is statistically significant. 


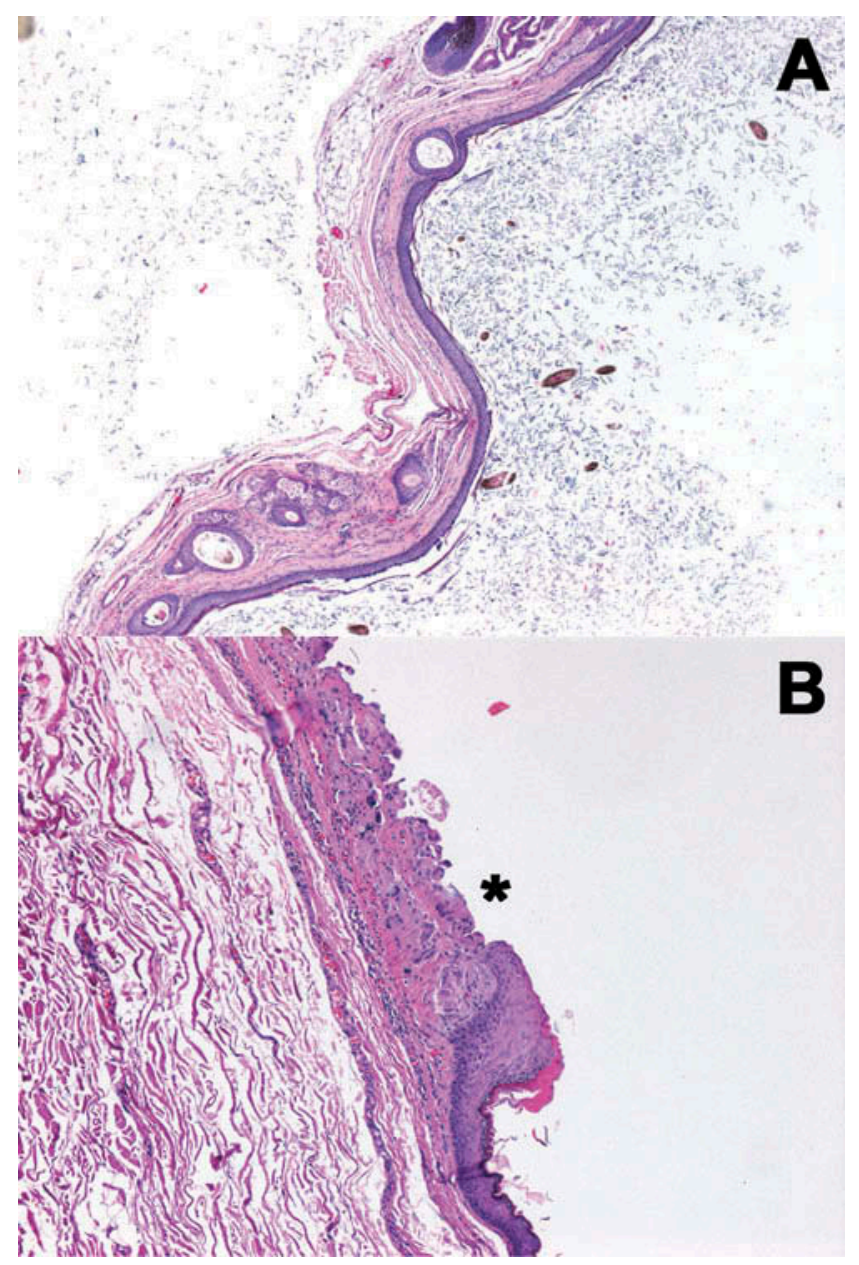

FIGURE 1. (A) Non-ruptured dermoid cyst wall with skin appendages (X50 H\&E); (B) histopathological image of a ruptured dermoid wall before surgery (* denotes the area of discontinuation of the wall) (X100 H\&E).

TABLE 2. Radiological features of orbital dermoid with and without rupture before surgery.

\begin{tabular}{|c|c|c|c|c|c|c|c|}
\hline & & \multicolumn{4}{|c|}{ Spontaneous Rupture } & \multirow{3}{*}{$\begin{array}{c}\text {-Univariate Logistic Regression } \\
\text { OR }(95 \% \mathrm{CI})\end{array}$} & \multirow[b]{3}{*}{$p$ (Wald Test) } \\
\hline & & \multicolumn{2}{|c|}{ Yes } & \multicolumn{2}{|c|}{ No } & & \\
\hline & & Number & $\%$ & Number & $\%$ & & \\
\hline \multirow[t]{2}{*}{ Location of cyst } & Medial & 14 & 53.9 & 6 & 37.5 & \multirow[t]{2}{*}{$1.94(0.55-7.26)$} & \multirow[t]{2}{*}{0.3057} \\
\hline & Lateral & 12 & 46.1 & 10 & 62.5 & & \\
\hline \multirow{2}{*}{ Depth of cyst } & Deep & 4 & 15.4 & 1 & 6.3 & \multirow{2}{*}{$2.73(0.36-56.2)$} & \multirow[t]{2}{*}{0.3549} \\
\hline & Superficial & 22 & 84.6 & 15 & 93.7 & & \\
\hline \multirow[t]{2}{*}{ Bone scalloping } & Present & 17 & 65.4 & 4 & 25.0 & \multirow[t]{2}{*}{$5.67(1.50-25.3)$} & \multirow[t]{2}{*}{0.0097} \\
\hline & Not present & 9 & 34.6 & 12 & 75.0 & & \\
\hline \multirow[t]{2}{*}{ Cyst contents } & Fat & 14 & 53.9 & 13 & 81.3 & \multirow[t]{2}{*}{$0.27(0.05-1.08)$} & \multirow[t]{2}{*}{0.0809} \\
\hline & Fluid/Mixed & 12 & 46.1 & 3 & 18.7 & & \\
\hline Size of the cyst (mm) & Median (min-max) & \multicolumn{2}{|c|}{$16(6-36)$} & \multicolumn{2}{|c|}{$10.5(2-25)$} & $1.08(0.99-1.19)$ * & 0.0755 \\
\hline
\end{tabular}

*Odds ratio per unit change in regression.

$p<0.001)$. Bone scalloping was significantly more common $(p=0.0097)$ in patients with spontaneous rupture $(65.4 \%$ of patients) (Figure 2$)$. The odds- ratio value (5.67) shows that the chances of spontaneous rupture increased by $467 \%$ when bony changes were detected. In contrast, the presence 

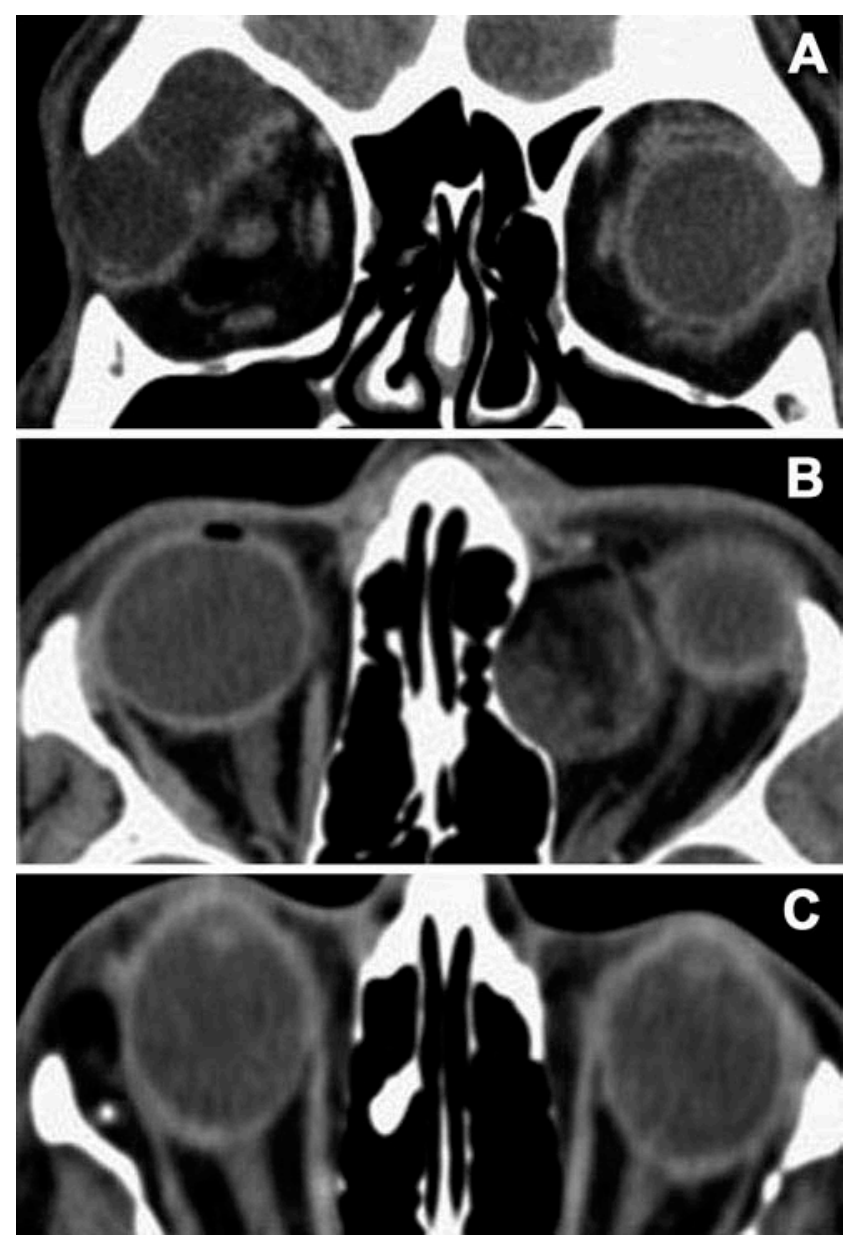

FIGURE 2. (A) Ill-defined deep dermoid with bone scalloping; (B) heterogeneous content, medial wall scalloping; (C) axial non-contrast computed tomography (CT) scan showing a dermoid cyst without signs of rupture, with a fat content and a well-defined outline with tiny calcifications.

of fat had a protective effect against rupture, reducing by $73 \%$ the odds of preoperative rupture.

\section{DISCUSSION}

The tissue reaction induced by leakage of the contents of ruptured DCs is well-recognized. Consistent with the present histology evaluation, giant cells with a slightly foamy appearance surrounded by sebaceous material are typically found in or adjacent to the capsule. ${ }^{4}$ Ruptured DCs do not collapse because the inflammatory infiltrate induces a pseudo capsule around the cyst, creating a barrier which prevents further leakage of the cyst's contents. ${ }^{4}$ The mechanisms implicated in DC rupture are not clear.

The detection of an eventual spontaneous dermoid rupture is theoretically important because the resulting fibrosis and adherence to the surrounding tissues may complicate a clear definition of the excision plane, causing damage to otherwise healthy orbital soft tissues. In the present case series, presurgical rupture occurred in $61.9 \%$ of the DCs, a rate within the 30 to $75 \%$ range reported in the literature. ${ }^{1-4}$

It is important to note that only one patient (3.8\%) with spontaneous rupture showed clinical signs of inflammation, which correlated with the presence of severe inflammation histopathologically. Although rupture of the cyst's capsule results in contact of cyst contents with the surrounding tissues, most cases are asymptomatic. ${ }^{4}$

On CT scans, DCs are observed to be orbital unilocular cystic lesions with different densities, depending on their composition. The radiological appearance of DC contents is an important clinical parameter. A DC filled with fat has a $73 \%$ lower 
chance to leak than a cyst containing only liquid. The presence of bony changes appears to be the most sensitive sign associated with spontaneous rupture. In our sample, bony scalloping was highly associated with spontaneous cyst rupture.

In the current study, the vast majority of the lesions were superficial in both groups; they were detected early in the first year of life and removed during childhood. Deep dermoids, on the contrary, are diagnosed only when they grow enough to produce proptosis. Taking into consideration that the median age of our patients at the time of surgery was only five years and the size of the cyst increases linearly with age, it is possible that the rate of spontaneous rupture would increase if the patients were older.

In conclusion, our data suggest that DCs with radiological evidence of fat content without bony scalloping may be observed and removed relatively later in childhood. Deep dermoids with liquid content and radiological signs of bony changes should be resected as soon as they are diagnosed.

\section{DECLARATION OF INTEREST}

The authors report no conflicts of interest. The authors alone are responsible for the content and writing of this article.

\section{REFERENCES}

1. Shields JA, Kaden IH, Eagle RC Jr., Shields CL. Orbital dermoid cysts: Clinicopathologic correlations, classification, and management: The 1997 Josephine E. Schueler Lecture. Ophthal Plast Reconstr Surg. 1997;13:265-276. doi:10.1097/00002341199712000-00007.

2. Bonavolonta G, Tranfa F, De Conciliis C, Strianese D. Dermoid cysts: 16-year survey. Ophthal Plast Reconstr Surg. 1995;11:187-192. doi:10.1097/00002341-199509000-00005.

3. Colombo F, Holbach LM, Naumann GO. Chronic inflammation in dermoid cysts: A clinicopathologic study of 115 patients. Orbit. 2000;19:97-107. doi:10.1076/0167-6830(200006)1921PFT097.

4. Abou-Rayyah Y, Rose GE, Konrad H, Chawla SJ, Moseley IF. Clinical, radiological and pathological examination of periocular dermoid cysts: Evidence of inflammation from an early age. Eye. 2002;16:507-512. doi:10.1038/sj.eye.6700045. 